\title{
Power Relationships: Marginal Cost Pricing of Electricity and Social Sustainability of Renewable Energy Projects
}

\author{
Sunderasan Srinivasan ${ }^{1}[$ \\ Received: 24 January 2019 / Accepted: 30 October 2019 / Published online: 12 November 2019 \\ (C) Springer Nature Singapore Pte Ltd. 2019
}

\begin{abstract}
The days of Feed-in-Tariff programs to promote Renewable Energy (RE) capacity addition might be behind us. With RE generation constituting increasing proportions of the generation mix across several markets, and attaining capacity levels that are sizable enough to influence the price discovery process on wholesale markets, RE generation is most likely to be compensated at or close to marginal costs of production in the years to come. As a fall-out, this might render several present-day utility-scale generation projects unviable (RE as well as conventional; "stranded assets"). Additional revenue opportunities would need to be identified for the projects to stay competitive, and for the projected environmental benefits from RE projects to continue to flow. Such revenue opportunities are likely to emanate from focusing on the social sustainability of RE projects. Revenues could be generated from increasing the non-consumptive use of RE assets through tourism initiatives, through integrating with popular culture and advertising, complementary-product production, and the like, subject to the prevailing circumstances at, and in the vicinity of, the project sites concerned. The relative proportions of revenues generated from consumptive and non-consumptive use of the asset are known to be a function of the socio-economic conditions prevailing at the project location/s at various points in time over the life of the project. Such revenue mobilization might be necessary but not sufficient to sustain an otherwise unviable RE project. A capacity payment in return for offering the utility the option to draw power from the RE plant could serve as a floor for revenues from plant operation in addition to revenues from the sale of electricity and from societal association with the plant.
\end{abstract}

Keywords Consumptive use $\cdot$ Non-consumptive use $\cdot$ Existential use $\cdot$ Social sustainability $\cdot$ Marginal cost pricing $\cdot$ Competitive markets

\section{Background}

Over the past three decades or so, Renewable Energy technologies ("RET", used interchangeably with cleaner or sustainable energy technologies) have been viewed as sources of resilient, cost-effective and environmentally sustainable energy, and have rapidly emerged as crucial instruments in combating, and possibly reversing, global climate change (CC). Several governments across developed and developing

Disclaimer The views expressed in this article are of the author's views and do not necessarily reflect those of any organization.

Sunderasan Srinivasan

sunderasan@yahoo.com; sunderasan@verdurous.in; http:// www.verdurous.in

1 Verdurous Solutions Private Limited, 154, Preethi Layout, Bogadi Village, Mysore 570026, India countries have offered a range of incentives to encourage the development, deployment and operation of RET based projects. Feed-in-tariffs ("FiT") - the offer of above-market tariffs to incentivize RE electricity generation - have been the most common, and perhaps most effective among incentive schemes in terms of encouraging rapid growth in installation volumes. FiT schemes were believed to be simple, transparent and democratic as they rewarded actual power generation, (as opposed to capital subsidies or fiscal incentives such as "accelerated depreciation" that supported the procurement and installation of equipment, but did not necessarily motivate investors towards the efficient operation of such equipment), and as the costs of the scheme were spread across all ratepaying electric utility consumers [35].

The favourable, technology-specific, and on occasion location-specific tariffs, were necessary to buttress emerging technology options such as solar photovoltaic technologies $(\mathrm{PV})$ and wind energy generation, relative to entrenched 
incumbents such as coal, oil and gas, hydro, and perhaps nuclear energy and it was always known that such support was likely be withdrawn when the 'alternative' achieved cost-competitiveness relative to the incumbent, or sooner, when the contracting authorities exhausted budgetary provisions. While FiT and other schemes were designed to help scale installations up and consequently to bring prices of RET hardware and services down, "carbon pricing schemes" were intended to value and to internalize the favourable environmental externality, and to make the power generated from incumbent coal and oil fuelled plants more expensive in comparison, thereby accelerating such convergence. In all, attempts had been made to help investors earn comparable risk-weighted returns after adjusting for relative environmental costs and benefits.

By assuring project developers of stable revenues, in short order, FiT schemes accelerated the cost reduction of RET through scale economies in project operations, and through attracting large investments into upstream manufacturing processes, logistics, and into value-chain optimization. Needless to mention, even as FiT might have directly contributed to the rapid growth in PV and on-shore wind installations, fixed effects such as culture and environmental concerns might have played a part in magnifying the outcomes from FiT schemes reported, especially across several European countries [24].

For most part of the FiT era, however, achieving social sustainability remained lower in the pecking order for most stakeholders. This paper seeks to highlight the significance of social involvement and to address the gap in literature on the subject. If such trends were to continue unabated, rapidly declining costs and briskly growing installation volumes might result in an abundance of low-marginal-cost power, enhancing consumption and triggering adverse environmental and social consequences in their wake. van den Bergh et al. [48], for instance, have listed increased fertilizer production, application and run-off as a fallout of supplying power at extremely low prices. This could further result in contamination of surface water, intensification of agriculture on marginal land, reduction in biodiversity, and alterations in migration patterns and increased competition for land among people, among livestock and among people and livestock. Finally, the authors list the need to manage and recycle ever increasing quantities of end-of-life equipment. Consequently, this paper develops the roadmap for social sustainability in the era when marginal costs of generation from RE plant determine power sector tariffs, which ironically might be insufficient to ensure viability of several operating incumbent technology power plants as well as RE projects.

\section{Low Marginal Cost Generation and Price Determination}

The share of electricity generated from renewable sources was projected to grow from 24\% in year 2016 to $30 \%$ in year 2022
[1]. With the progressive phasing out of fossil-fuel-fired plants, the low-marginal cost RE options are most likely to determine the standard for prices of all generated power. RE systems by definition required high upfront capital investments, alongside incumbent thermal or nuclear power plants and hydro-electric projects. However, over the lifetime of the project, the marginal costs of operating the asset and of generating electricity were relatively low, and included for instance, replacing select PV modules or inverters for solar PV projects and periodic lubrication and general maintenance for wind-turbines, and the like. Larger repairs and component or sub-assembly replacements were more likely to be covered by insurance contracts. The evolution in fuel costs and sustained feedstock availability have played a relatively larger role in sustaining the viability of biomass / biogas projects, while the royalty charged on water-use has affected the attractiveness of hydro-kinetic plants in certain jurisdictions.

However, the era of feed-in-tariffs to develop RE markets might be behind us [1]. Since the launch of the German solar PV "rooftop programs", several project developers and equipment manufacturers are known to have focussed on growth even at the expense of profitability. ${ }^{1}$ With progressively lower tariffs on offer, the focus would therefore need to shift to managing liquidity and to avoiding bankruptcy. Eventually, support to research and development, manufacturing tax breaks and renewable energy purchase mandates ("portfolio standards") and the like may be phased out. RE projects would need to identify the means to generating financial returns, through and beyond clean energy generation itself, [19].

It was estimated, for instance, that a $10.0 \mathrm{MW}$ onshore wind energy project built in the United Kingdom (UK) in year-2031 was likely to generate just about two-thirds the revenue that a project built in year-2018 was likely to earn from the sale of electricity. Likewise, a 5.0 MW solar photovoltaic project (also in the UK), was likely to generate marginally over three-quarters of revenues that a similar year-2018-installation was likely to earn from the sale of electricity [14]. Similar studies modelled a 40\% RE penetration rate within the United States (US) and had projected that wholesale prices could decline by about $25 \%$ or more relative to contemporary prices, [36].

With the rapid declines in costs of installing and operating $\mathrm{RE}$ assets, and with the increasing numbers of producer-selfconsumers, (frequently referred to as "prosumers") electricity generation might have entered a competitive phase, ${ }^{2}$ resulting in subsidy-free bids in certain jurisdictions and in low, zero and even negative power prices on wholesale markets in other situations [32]. Such "cannibalisation" might be viewed as a

\footnotetext{
${ }^{1}$ See for instance, Srinivasan [45].

${ }^{2}$ From time to time, several Indian states have conducted auctions for adding RE (more specifically solar PV) generation capacity but have held back on executing power purchase agreements with the successful bidders, ostensibly to try and procure power at lower prices discovered in subsequent rounds of bidding.
} 
signal that prices in these competitive markets might be driven by the marginal costs of generation, transmission and distribution. Further, on-site or captive generation by commercial and industrial consumers themselves might lower the latitude for cross-subsidization by utilities, thereby reducing the price differential between the highest and lowest tariffs.

Additionally, priority dispatch for wind and other RE sources was no longer mandated in the UK, Sweden and Denmark, and it was reported that such priority might not be available in several other countries in the near future, [25]. When the "merit order" was in effect, the lowest marginal cost electricity (such as from solar PV, wind etc.) was dispatched first, while the higher marginal cost electricity dispatched last set the spot price - the price discovered on the markets for all technology options, [7]. In other words, the higher marginal cost options determined the price of all electricity.

Viewed from the perspective of a resource-allocation decision, revenues from the sale of electricity would continue to be fundamental in appraising an RE project, depressed as they might be. As the market turns increasingly competitive, however, additional revenues would need to be "captured" for the $\mathrm{RE}$ projects to remain viable. This is the fundamental hypothesis of the persent research effort. Appraisal of RE projects has consequently got to migrate away from traditional assumptions relating to homogenous markets and assured demand models and would need to accommodate multiple motivations and local value systems.

Rather paradoxically, therefore, despite falling equipment prices and given projected demand patterns, partly owing to the withdrawal of subsidies and incentives, the ruling wholesale prices for supplied power are projected remain consistently low, working to the disadvantage of the RE generators. Unsubsidized RE projects might cease to be viable by the 2030 s as a result. In principle, increasing proportions of electricity generated from RE sources might also signal the departure from traditional reward structures based on "levellized cost of electricity" (LCoE) computations, and might indicate that low-carbon electricity was to morph into the new normal and was likely to acquire the characteristics of a generic "commodity" sold within competitive markets.

\section{The Cost and Tariff Conundrum}

The FiT / subsidy support provided to RET has spurred large-scale RE installations and has increased electricity supply on windy and sunny days, lowering electricity prices in wholesale markets, on occasion, driving prices below zero in certain markets. Ambec and Crampes [3] however argue that the intermittency in generation from RE sources, especially wind turbines and solar photovoltaic systems ("Solar PV" or just "PV") has necessitated back-up installations including fossil-fuel burning plants or large-scale storage units which need to grow in tandem with volumes of RE installations. They further argue that "cheap electricity" was not necessarily good for the climate when viewed as a part of a system, specifically because such back-up from "base load" generators was necessary. They believe that FiT-induced RE generation might be necessary but not sufficient to curtail emissions from power generation. The low prices, combined with the use of potentially polluting options to cope with the intermittency of RE generation, have meant that electricity consumption was still high enough: the authors advocate driving retail electricity prices higher, perhaps through taxes on emissions from combusting fossil fuels to try and moderate demand through more efficient utilization.

Likewise, Imelda, Fripp and Roberts [26] observe that subject to certain assumptions relating to the elasticity of power demand, variable pricing on the demand side, in a fossil-fuel dominated generation system could serve to limit peak demand. On the other hand, the authors believe that in an RE system dominated, variable consumer-end pricing could lower the cost of day-night balance (including the cost of building storage), help limit the addition of generation capacity, and could forestall demand during resource-lean times, while allowing higher electricity use in tandem with peak generation.

In India, for instance, amendments proposed in year 2018 to the National Tariff Policy (2016) mandate that electricity generation, transmission and distribution firms pass on benefits of low-cost of depreciated assets to consumers through reduced tariffs [44]. The prices paid by end-users across countries and regions, might however, continue to be determined by a range of socio-economic and political considerations, and technical compulsions including transmission and distribution losses ("T\&D losses"), spread between the mean and peak demand, and the like. This divergence between tariffs paid to generators and the tariffs charged to end-use consumers is projected to work to the disadvantage of the generators.

This paper, however, seeks to explicitly focus on the generation side of the supply chain and not on end-user pricing, and is motivated by the prospect that several $\mathrm{RE}$ projects might struggle to operate at pure marginal cost pricing of exported power. The power purchase agreements (PPA) executed at about the turn of the millennium, for instance, assuring some 28,000 wind turbines installed in Germany of premium tariffs for 20 years were scheduled to expire commencing year2020. The feed-in-tariffs built into these power purchase agreements were sized to compensate for the high unit costs of turbines and low operational efficiencies given the stage of technology and market development $c a$ year 2000. In year-2020 alone, some 4500 turbines were likely to be decommissioned. From then on, each year, 
some $2400 \mathrm{MW}$ of installed capacity, owned by a broad range of individuals, farmers, cooperatives etc., was scheduled to grow ineligible to receive the premium tariffs, [22]. The decision to decommission these wind farms might suggest that the marginal-cost based tariffs that might be on offer $c a$ year 2020 might be insufficient to meet the operating costs of the fully-depreciated and presumably debt-free wind farm projects.

New corporate power purchase agreements helped extend the life of a few of these RE projects, especially cooperative-owned projects, whose guaranteed payments under promotional schemes were scheduled to end after year-2020. Such deferment in decommissioning serve to keep the countries' installed base intact while also sustaining the financial viability of the RE projects [21]. These corporate purchases were apparently motivated more by the desire to draw and use ' $\mathrm{CO} 2$-neutral' energy, and to try and benefit from the image associated with such climate consciousness, and to a lesser extent by the corporate body's need to conserve on electricity related expenses. These reconditioned RE assets, depreciated and presumably debt-free, were however, required to compete against more efficient contemporary equipment which called for newer valuation and pricing techniques, and it was believed that the newer power purchase agreements were to keep them working for a relatively short period of about 3-5 years.

The sites could be repowered with larger and more efficient new-generation turbines that could benefit from the availability of wind-resource data and the existing transmission infrastructure among other things, but such investments would have to be justified on their own merits along the lines of new projects and at the tariffs on offer at the time of project development. For instance, in the face of falling costs, growing wholesale market exposure and narrow margins for power suppliers, seven wind farms in Iowa in the USA, commissioned between years 2004 and 2008, were being repowered at a cost of about USD 1.0 billion to increase annual output by some $19 \%$ - 28\% through the use of more efficient turbines and components and to benefit from production tax credits made available. The ten-year production tax credits were extended in year 2016 and were scheduled to decline by $20 \%$ each year and consequently, projects started in year 2018 were eligible for USD 13.80/MWh in credits. When combined with energy prices set at USD 24.0 / MWh and capital expenditures at USD $950.0 / \mathrm{kW}$, the repowered projects were projected to earn internal rates of return (IRR) after tax of some $11 \%$. Simultaneously, the project developer also believed that owing to near constant capital costs, declining tariffs and the dwindling tax credits, margins for projects constructed subsequently might decline progressively. Likewise, wind energy generation projects in Washington, Texas and other US states were being evaluated for repowering and upgrades and for the installation of analytics, monitoring and forecasting systems [17], to try and benefit from the tax credits and other incentives that might not be available for long.

\section{The Need to Focus on Social Sustainability in an RE-Dominant Energy System}

In general, infrastructure investments are presumed to contribute to social and environmental objectives over and above merely meeting the threshold for economic returns; such secondary returns could include local employment generation, social cohesion and mitigating and possibly even reversing climate change [18]. Evaluating a prospective infrastructure investment, including RE project investments, would therefore mean and include considering social and ecological outcomes simultaneously with economic returns. Favourable environmental outcomes from the deployment of RET, frequently relative to a projected counter-factual, have been quantified and viewed as additional sources of revenues that might elevate a marginal project past the threshold into profitability. Attempts have been made to trade such externality to generate tangible cash-flows for RE projects registered under the UNFCCC / Kyoto Protocol flexibility mechanisms and other such schemes.

Economic benefits from premium tariffs, renewable portfolio standards and the like, aimed at promoting cleaner energy technology, have hitherto been computed based on average costs of generation over the life of the project asset (LCoE). Until recently, cleaner energy projects appeared technologycentric and generally operated in isolation from society around them, billed as initiatives with superior environmental credentials in certain high income countries, and as quickly realized electricity generation capacity increments in emerging economies. The premium tariffs paid to reward RE projects for their environmental credentials have progressively dwindled in keeping with larger scales of production and installation and the consequent decline in project development and implementation costs. For instance, starting $c a$ year-2014, the 696.15 kWp Martifer Solar PV project supplying power to IKEA's store in Pisa, Italy, offered a discount relative to the applicable utility tariff for electricity supplied. The avoidance of some 373 t of CO2 each year (relative to a business-as-usual benchmark) was apparently overlooked and the environmental externality generated was not rewarded [41]. Given such prospects, eventually, the focus would have to shift to aiding regional competitiveness, attracting industries preferring lowcarbon heat and electricity, and consequently to local employment generation. Appraising energy project investments would therefore, need to include intangible social value generated beyond narrowly-defined project boundaries. 


\section{Working towards the Social "Acceptance" of RE}

The existing geophysical landscape might guide the installation as in locating compressed air storage facilities, hydro power plants or wind farms and the like, while the installations, in turn, leave an impact on the landscape. Wolsink [49], believes that creating space for the infrastructure relating to an RET package, especially the likes of transmission lines, is largely about landscape issues, landscape variations and landscape values. Likewise, Scognamiglio [42] suggests that in addition to maximizing energy generation at a given site, ground-mounted solar photovoltaic plants should pursue landscape objectives. Studies attempting to assess people's perceptions of wind turbines and solar arrays have reported that beyond visibility, 'acceptability' stemmed from the potential for a loss of amenity, or from whether the central character of landscapes was altered by 'technology intrusion'. Ladenburg [30] observed that perception of wind power generation was influenced by prior experience with the visual impacts of [offshore] wind farms and that the favourable impression, or otherwise, of future wind farms was a function of the location and visual impacts of existing wind farms.

Even as RE is frequently touted as a relatively straightforward means to achieving mitigation and possibly reversal of climate change, local opposition to RE installations and transmission infrastructure might stem from genuine concerns and local issues, or from mere ignorance and misinformation, [5]. Wind turbines installed within the arid grasslands of the Thar Desert in the North-Western Indian state of Rajasthan, for instance, have posed serious threats to the highly endangered Great Indian Bustard. The [Indian] National Green Tribunal banned the installation of wind turbines in year-2016, while the Wildlife Institute of India had advised wind turbine project operators to install "bird diverters" spaced five meters apart and to reroute cables, perhaps taking the cables underground. Options to relocate the wind turbines to less eco-sensitive zones outside of the Desert National Park were also discussed, [46].

In other situations, fearing local undercurrents and possible political strife, authorities concerned, interest groups or utilities might stymie progress with RE project implementation. Independent power producers (IPP) in South Africa, for instance, won the right to build power plants in year 2015 as a part of the government's RE-IPP Procurement Program (REIPPPP). In year 2016, however, Eskom, the electricity utility and transmission monopoly, refused to sign power purchase agreements with the 27 companies that had won the awards through the bid process. The utility believed that existing generation capacity was, by itself, more than sufficient to meet demand, while the proposed RE capacity was to supply power at prices that the utility could not afford.
Following this, in year 2017, Eskom released statements to the effect that five of its coal-fired power plants would need to shut operations down to create room for the proposed RE projects, potentially shedding some 30,000 jobs. Additionally, for fear of losing the source of their members' livelihoods, the forum of coal trucking companies contracted by Eskom sought to prevent Eskom from signing contracts with RE companies, [23]. Eventually, when the power purchase agreements were executed, policy makers insisted on high levels of "local content" within projects, so as to stimulate local entrepreneurship, local manufacturing and local employment, [15], irrespective of whether such mandates were benefit-maximizing or even practically viable.

In other situations, local considerations might be more cosmetic than substantive. Climate- friendly projects might be seen as impinging upon the daily lives of residents and mere inertia might lead to passive resistance, while climate change and related aspects might be perceived as a geographically removed and temporally distant problem. Officials at Ocean City, Maryland, USA, rejected the offer of free electricity from a 32-turbine offshore wind farm planned 17 nautical miles from the shore. The Mayor and sections of the city's residents feared that an offshore wind farm within 30 miles of the resort town's shore might harm tourism. The project developer's general counsel argued that Ocean City was placing "the interests of few before the interests of many" [13]. There might be merit in paying more attention to the practical aspects of project-related communication and its relevance to interest groups, even when the information provided might be technically correct.

Clearly, "the politics of the everyday" might be visible in the working of interest groups and sections of the project's stakeholders. When the focus of energy projects shifts to social sustainability, therefore, the "messiness of everyday life" and the diversity of clients needs to be respected and a "needs-based" bridge between the energy market and everyday practices needs to be built, [34]. In other situations, 'affected' local communities might react and oppose installations, not necessarily to the specific RET deployed or proposed for deployment, but to the decision-making process that excluded them. Clearly, balancing between environmental objectives and social justice is not as straightforward. Researchers believe that even if local communities were not consulted during the project design process, given that energy infrastructure alters spaces, expectations, feelings and habits of residents, for them to oppose or to accept, or to relate to energy infrastructure in one way or another, might be considered "outsider participation".

Povitkina [40] believes that corruption within a democratic set-up could have a moderating effect on long-term projects 
aimed at mitigating climate change. Lobby groups might hamper the expansion of RE capacity, or on occasion, might have sound designs replaced by less viable propositions which might not serve the silent majority well. She goes on to contrast Brazil with Germany and concludes that the effective enforcement of standards in Germany, strong and independent monitoring and high compliance had contributed to achieving political commitments to long term climate goals. Ensuring non-tokenism to the local people and making certain that demands and concerns are debated openly calls for a delicate balance, but one that might serve the project well in the long run, yielding a contextually relevant and optimal design on the one hand, and eventually, cooperation from the project affected communities during the operational tenure of the project.

Nadaï \& van der Horst [38] advance the argument that existing landscapes combined with newer RE installations could offer hitherto unavailable opportunities for discovery and conservation. For instance, the authors believe that wind power development had provided birdwatchers with resources to undertake surveys and has helped map previously unknown bird habitats or even to discover previously unknown species, thereby uncovering new information about birds and bats. They argue that the RE installations shape a new landscape and the birds or other inhabitants develop new coping strategies and renew their relationship with the wind or other shared common resource.

Such consensus building might sometimes be referred to as "democratic associationalism" and entails a real and immersive partnership with the project's stakeholders [4]. Unfortunately, such consensus building might not be as straightforward, for, public perception relating to a project might not be consistent, and might evolve over time, possibly even swinging between extremes ranging from opposition to implementation to opposition to dismantling of the same asset, driven initially by apprehensions and subsequently by an appreciation for the value delivered by the project. Resistance to change - material or symbolic - might be implicit in routine actions and inertial living styles, and drawn from cultural prejudices, folklore, inadequate information, misinformation or perceptions rather than from reality, but might rarely be expressed verbally or succinctly. Also, opposing views might be expressed by individuals when consulted in isolation relative to when interviewed as a part of a group of peers, [43]. While the environmental dividends from RE might be global, and on occasion, notional and computed relative to a presumed counter-factual, the social dividends to be delivered by the project are undeniably local, and often tangible. There might therefore be a need to fit RET into practices rather than into places [5] and to look beyond a binary accept-reject framework.
Non-CONSUMPTIVE Use of RE Project Assets: Cases from Tourism and Popular Culture

While local residents might fear a loss of amenity from new energy projects or might detest the visual impact of existing infrastructure including wind turbines, transmission lines, cooling towers and the like, perceptions of tourists could be significantly different from those of residents. Open-pit coal mines, nuclear power plants or wind turbines could serve to attract tourists owing to their uniqueness. "Energy tourism" could involve visits to former, regenerated or operational energy sites with activities customized to attract and engage tourists and could be blended with heritage tourism, farm tourism and adventure tourism [20]. A nuclear power station that was built in Kalkar on the border between Germany and the Netherlands, but one that was never commissioned, attracted half-a-million visitors each year through allinclusive holidays, and facilities comprising hotels, restaurants and merry-go-rounds. The most popular attraction at the site, though, was a cooling tower with a climbing wall outside and a carousel inside. Likewise, Ferropolis, the 'City of Iron' located on a former, open cast, lignite mine in the Eastern German state of Saxony-Anhalt showcased abandoned metal structures, immense excavators and towering cranes, while the roof of a former workshop itself was covered with solar photovoltaic panels to power the museum's operations and annual summer music festivals, [37].

Similarly, in the southern Indian state of Kerala, the Kerala State Electricity Board (KSEB), the electricity utility, had sought to increase non-tariff income through tourism related activities at its energy assets. As of June 2018, KSEB managed a total of 58 large and small dams in the state. The Kerala Hydel Tourism Center (KHTC: www.keralahydeltourism. com), a subsidiary promoted by the Board had developed a project at the Idukki dam, India's only arch dam and one of the highest dams in all of Asia, at an estimated cost of INR 260 million ( USD $4.0 \mathrm{~m}$ ). Further, KHTC had proposed a laser show depicting the history of the state and the evolution of the utility, with the concave surface of the dam serving as a screen. An amphitheatre and an aquarium were also proposed as a part of the project. In all, KHTC had initiated tourism related activities at 21 dam sites. The boating centre at Banasura Sagar dam in Wayanad district attracted close to a million visitors during April 2017 - March '18. The Center earned revenues of about INR $150 \mathrm{~m}$ ( $\sim$ USD $2.30 \mathrm{~m})$ in fiscal year ending March 2018. A 40-acre tulip garden near the Kundala dam in Munnar and a cruise service between Anchuruli and Kulamavu in the same district were on the anvil. Proposals to build amusement parks at seven dam sites were being assessed [16].

In a bid to popularize RE-Tourism more specifically, the German Federal Foreign Office funded the travel guide Germany - Experience Renewable Energy, a volume edited 
by the German RE Agency (“AEE”) which details some 200 RE sites, some of which overlapped with typical holiday destinations. RE assets ranging from near-shore wind farms and energy trails in low mountain areas and a hydropower plant on the Swiss border and the like, are slated to create additional income opportunities for residents across 16 states [2]. At $€ 16.99$ plus shipping, the guide had been quite popular among potential tourists. One of the RE assets discussed within the guide was the 90.0 MW Holtriem Wind Farm in Germany's Lower Saxony, which was the largest wind farm in Europe at the time of its commissioning. The observation platform for tourists on one of the turbines, $65 \mathrm{~m}$ above the ground, provided "stunning views" of the North Sea and the East Frisian Islands. The residents of nearby Juehnde village had built a New Energy Center to showcase the energy self-sufficiency achieved through the combined heat and power installation, [37].

Evidently, RE tourism infrastructure and services could include observation towers, nature trails, environmental education and interactive science experiments, combined with outdoor activities for entire families and adventure seeking tourists. RE tourism could provide a 'novelty factor', attracting people to do 'something different' and spend time 'away from the usual places' and to enjoy a modern visual experience. The viability of energy projects could be enhanced through offering such event and experience tourism for a range of tourist segments, including perhaps, through hosting wedding ceremonies for technology enthusiasts and others [20]. Local communities benefit from the visibility in general, but more specifically from the extended stays and increased spend by tourists.

The Contra Dam across the Verzasca River in Ticino, Switzerland supporting the 105.0 MW Verzasca Hydroelectric Power Station operated by Verzasca SA hosted a world record setting bungee-jump-from-a-fixed-object at the time, a stunt filmed for the year-1995 English language film Golden Eye. This stunt was voted the best motion picture stunt of all time in a year-2002 survey [33]. Television reality shows and scenes within movies from across the world have since been filmed at the dam. Following the interest generated by the film, commercial bungee jumping was permitted at the dam site and by year 2018, individuals were charged between CHF 195 (10 to 19 years of age), and CHF 255 (for tourists aged 20 and above) for a jump, including the 'dam jump charge'.

Likewise, the multimedia exhibition center about wind energy utilization at the Whitelee Wind Farm Visitor Center in Scotland, combined with some $130 \mathrm{~km}$ of marked trails intended for hikers, cyclists and horse riders received some 75,000 visitors each year. The Cruachan Power Station Visitor Center in Oban, Scotland, UK, built in year 1959 near a pumped-storage hydro-power plant which also helped access the higher part of the Cruachan Horseshoe mountain range was visited by some 60,000 tourists each year, [6].

\section{Revenues from Complementary Use}

Over the past decade, the prices of solar PV equipment in general, and of solar PV modules in particular, have declined sharply, largely owing to scale economies derived at the large manufacturing units located in China. In situations where the environmentally-sustainable project might be profitable on its own merits, it might be difficult to make the case for monetizing externalities and from thereon for seeking credit for GHG mitigation. Hence several agencies like the Cochin International Airport (cial.aero), in the southern Indian state of Kerala, have had to look elsewhere to maximize the benefits from the plant.

The 13.10 MW solar PV power plant covered an area of 52 acres $(210,437$ square meter) of land near the cargo complex, making it the first wholly solar powered airport in the world. ${ }^{3}$ The climate-friendly initiative was well received by all stakeholders concerned, but installing the power plant also meant surrendering alternative options for utilizing the land for the foreseeable future. This motivated the airport to explore the possibility of engaging in "organic" farming - without the application of chemical weedicides or pesticides - to utilize the vacant areas in between the solar PV arrays. Such farming was expected to arrest weed growth between the arrays, and in-turn, to help reduce shading on the arrays. The planting of vegetables also cooled the panels and reduced dust accumulation, thereby helping augment power production from the solar arrays [12]. The water used to wash the solar PV panels also served to irrigate the rows of vegetable plantations. The airport produced some $40,000 \mathrm{~kg}$ of vegetables during year 2016 and some $80,000 \mathrm{~kg}$ of vegetables during year 2017 . The airport employed some 8000 persons and the vegetables were sold to the staff on priority; surplus stock was made available for sale to passengers. The company responsible for operating the solar PV power plant had reported total revenues of INR 150,657,000 in year-ending March 2017; revenues from vegetable sales would thus constitute some $0.5 \%-1.0 \%$ of total revenues generated.

Clearly the attractiveness of a site and the extent of the contribution made by tourism revenues to sustaining viability of the project is a function of the rarity of the technology applied, magnitude of the installation, and other site-specific attributes. The Blue Lagoon geothermal spa on the Reykjanes peninsula in Iceland, some $45 \mathrm{~km}$ from the capital Rejkjavik is among the most popular tourist destinations in the country.

\footnotetext{
${ }^{3}$ The airport received the "Champion of Earth" prize for year-2018, "the highest environmental accolade" awarded by the United Nations for the leadership demonstrated in the use of sustainable energy.
} 
The Icelandic thermal baths that used 'wastewater' from the Svartsengi geothermal power plant attracted about a-third of all visitors to Iceland and tourist numbers had grown after the building of the plant. HS Orka, the company that owned and operated the spa also operated Svartsengi geothermal power plants immediately upstream, and HS Orka's revenues and valuation were based on the projected revenues from the sale of power generation, as well as revenues from hot and cold water sales and from other sources [27]. HS Orka, operating the Svartsengi and Reykjanes geothermal power plants and owning $30 \%$ of the spa reported revenues of about CAD 67.0 million for the 237 days to end-September 2018, but a comprehensive loss of close to CAD 31.0 million [28]. Pending more detailed disclosure, it is not immediately apparent if the sale of hot and cold water (geothermal power plant) or the sale of vegetables (solar PV power plant) was compensating entirely for the losses incurred or enhancing the profitability from the sale of energy alone.

\section{A Three-Part Tariff Scheme for Generators}

Several researchers have discussed the design of block tariff schemes for end-users (on the demand side) with a view to providing low quantities of electric power at low prices in the manner of providing society with a merit good. Tariffs are raised in tandem with increased consumption to try and moderate use on the one hand, and to efficiently allocate available supplies on the other. Ito [29] has found that consumers responded to average rather than marginal price which reduced the effectiveness of such non-linear pricing schemes and raising questions relating to the welfare implications of such schemes. Borenstein and Bushnell [8] analyze the relationship between retail residential electricity prices across US states and compare these prices with social marginal costs. The authors observe a large regional variation in the difference between the electricity rates and the utility's average social marginal cost even as they found a convergence between the two values when averaged across the country. Polo and Haas [39] have studied the feed-in-tariffs and the use of willingnessto-pay (WTP) from the perspectives of dissemination effectiveness, costs to the public, evolution of system prices, consumers' WTP and profitability for the consumer. The authors recommend that promotion systems need to consider consumers' WTP and balance it with the effects of technological learning effects.

In principle, the FiT is slated to encourage cost-effective RE deployment and efficient plant operations. Yet, few authors have studied the tariff schemes from the supply-side perspective beyond discussions relating to $\mathrm{LCoE}$ and evolution in equipment costs. Allowing for a reasonable return on investment (and providing a purchase guarantee), while eliminating arbitrage opportunity relative to the existing electricity market has been an inherent challenge of most fixed-price FiT programs. Basing on experience from across Europe and North America, Couture and Gagnon [11] have examined four 'market-independent' and three 'market-dependent' remuneration schemes: the authors believe that fixed price schemes, even when independent from more mainstream market prices, offer investment security to project developers and might be better suited for emerging technologies.

Projects employing well-established technologies might be in a better position to absorb greater uncertainty with revenue streams. Simultaneously, for projects where a large proportion of the total costs are invested up front and amortized over a decade of operations, or longer (even when employing mature technology options), being entirely at the mercy of volatile market prices might deter prospective investors. Yet, with RE generation responsible for a quarter to a-third of all power consumed in certain markets, RE projects do not merely take prevailing prices - they actually serve to define such prices through influencing the dynamics of supply and demand (for instance, [10]). It should also be borne in mind that when the quantum of electricity generated is range-bound and the tariffs are nearly fixed (as within FiT regimes), the 'upside' for equity investors is limited. This article therefore proposes an economically-efficient, three-phased compensation pattern which blends the efficiency of market-determined prices that help align generation and supply with patterns in demand, combined with the security of a fixed tariff that preempts the prospect of an arbitrage opportunity generated by the FiT in several markets, while optimizing welfare outcomes.

To put this in perspective, in keeping with the then prevailing market conditions, Lesser and $\mathrm{Su}$ [31] continue to treat RET as "alternative" and their tariff model continues to call for a four-step administrative action by policymakers. The present paper, in contrast, considers RE generation as "mainstream" and actually contributing to the discovery of market clearing prices. Additionally, a guarantee of total revenue certainty, as offered by a pre-determined feed-in-tariff offered for the life of the project assets, or thereabouts, is believed to eliminate the incentive to improve design, construction and operational efficiency.

Even as different RET developers might be faced with different cost levels, largely owing to differences in risk profiles and consequently in costs of project debt, the more costefficient developers and operators would enjoy greater profits from 'taking' market-determined prices; as a corollary, the less cost-efficient RET developers would be forced out of the market.

This paper therefore recommends the introduction of a three-component tariff scheme for RE generators to help cope with the increased competition in the market and to sustain operations beyond the FiT era. 
Fig. 1 Three components of tariff design: the market clearing price (=marginal cost of production), the marginal cost of RE production (not considering return-on-equity) to be earned from social sustainability, the return on equity (could be earned from fixed capacity payments)

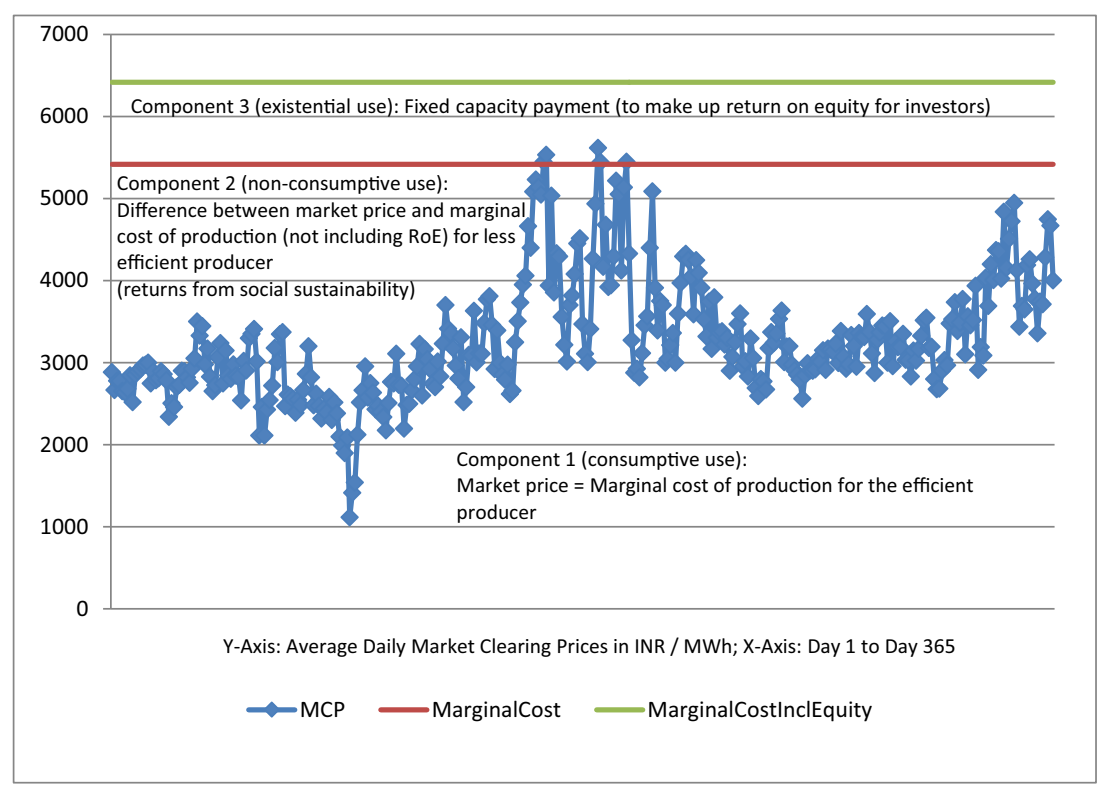

The first of three components of the tariff structure would be structured in the manner of a capacity payment: a price bid by prospective developers as a function of the capacity they bring to the market and a price paid for offering the utility with the 'option to draw' upon the power generated ("existential use"). With intermittent renewable capacity such as solar PV and wind dominating the generation mix, the quantum of the capacity ("option") payment should be determined more by the time-of-day at which the utility could draw the power - higher rates bid for supplies during peak hours and lower tariffs for offpeak hours. For instance, utility-scale, grid-connected solar PV projects might offer power at a lower capacity price for supply during sunshine hours - which might not necessarily overlap with peak demand hours for the utility. ${ }^{4}$ This difference in capacity payments could also provide incentives for the inclusion of storage capacity accompanying individual technologies and the optimal design of such storage. Even as solar thermal projects might be more expensive, when combined with molten salt storage, solar thermal projects might be better placed to meet peak demand and hence to command a premium capacity payment.

In a generation mix dominated by RE technologies, this capacity payment could also be held constant for the first 10 years or so and later be allowed to float on markets in the manner of a competitive price discovery process that would respond to market realities of the time.

In a generation mix dominated by RE technologies,

\footnotetext{
${ }^{4}$ Borenstein [9] finds that the market value of power generated from solar PV could command premiums of almost $30 \%-50 \%$ if such supplies were to be effected to meet peak demand.
}

this capacity payment could also be reduced as electricity generated by the plant breaches a pre-determined threshold within a pre-determined time period - different thresholds could possibly be set for the summer and winter months.

The second component of the tariff structure would be discovered on the markets - day ahead, term ahead etc., subject to the segment within which the project might seek to compete. Again, these could be short-term contracts or long-term contracts, and peak or non-peak prices subject to the aspirations of the parties to the contract. These contracts are more likely to be effected at marginal costs of generation and the technology options and projects with the lower marginal costs are likely to find buyers more readily ("consumptive use").

Most interestingly, the third component of such a tariff structure is slated to come from engaging with society locally as well as more dispersed - not dissimilar to the trading of environmental externality when RE technologies were still considered "alternative" ("non-consumptive use").

Figure 1 presents the three components of the proposed tariff-structure. In a competitive environment, the market clearing price (MCP) would represent the equilibrium price at which the sellers were willing to sell, and given the homogeneity of the underlying product and the virtually nonexistent barriers for large numbers of generators to enter and exit, the MCP might be presumed to represent the marginal cost of generation for the market as a whole. At the time of initiating a new RE project, the bidder could bid for a fixed capacity payment of notionally set at 1000 per MWh - making up for the deficit in returns on equity as shown. Individual 
producers would therefore need to mobilize additional resources from non-consumptive use of the plant to make up the difference between the market clearing price and the respective marginal cost of production.

Within the scheme described:

Total Revenue $=($ PlantSize $\mathrm{x}$ PLF $\mathrm{x}$ CapacityPayment $)$

+ (PlantSize x PLF x MarketPrice) + (NonPower Revenues)

Marginal Revenue per kWh $=\left[\right.$ Total Revenue $_{(\mathrm{y} 2)}-$ Total Revenue $\left._{(\mathrm{y} 1)}\right]$

$/\left[(\text { Output in } \mathrm{kWh})_{(\mathrm{y} 2)}-(\text { Output in } \mathrm{kWh})_{(\mathrm{y} 1)}\right]$

Total Cost $=($ Cost of Revenue $)+($ R\&D + SGA + insurance $)$

$+($ InterestExpense $)+(\operatorname{Tax})+(\mathrm{RoE})$

Marginal Cost of plant operation $/ \mathrm{kWh}$

$=\left(\right.$ Total $^{\operatorname{Cost}_{(\mathrm{y} 2)}}-$ Total $^{\left.\operatorname{Cost}_{(\mathrm{y} 1)}\right)}$

$/\left[(\text { Output in } \mathrm{kWh})_{(\mathrm{y} 2)}-(\text { Output in } \mathrm{kWh})_{(\mathrm{y} 1)}\right]$

For MR = MC, and if plant size, PLF and capacity payments were to remain constant, and if average market clearing prices (per $\mathrm{kWh}$ ) were to decline year-on-year, then the increases in costs, if any, owing to inflation or increases in interest rates would need to be compensated by corresponding increases in non-power revenues. It is therefore in the plantowner / operators' interest to utilize the full potential of nonpower revenues from the non-consumptive use of the plant irrespective of changes in costs of building and operating such plant.

\section{Concluding Remarks}

Over the years, RE generation has been compensated on the basis of average costs of generation computed over the projected life of the asset, and on estimates of electricity generated over time. Secondary revenue streams have emanated from quantifying and trading the environmental benefits, relative to a hypothesized counter-factual scenario. With RE generation scaling up as rapidly, with the widely-reported and dramatic decline in hardware costs and soft costs of installing and operating RE projects, and with RE generation representing increasing proportions of the generation mix, in the ensuing phase of the sector's evolution, electricity generated from RE technology is more likely to be compensated at or close to marginal costs of production (at the generation end of the value chain). Individual households and commercial clients might choose to generate power from captive generating units, and hence to disconnect from the utility's grid network. This might render several present-day utility-scale generation projects unviable (RE as well as conventional: "stranded assets"). Additional revenue opportunities would need to be identified for the projects to stay competitive, and for the projected environmental benefits to continue to flow.
This paper suggests that such revenue opportunities are likely to emanate from focusing on the social sustainability ${ }^{5}$ of RE projects. Revenues could be generated from increasing the non-consumptive use of RE assets through tourism initiatives, through integrating with popular culture, especially mainstream cinema, and through such other opportunities as advertising, complementary-product production etc. subject to the prevailing circumstances at and in the vicinity of the project sites concerned. The relative proportions of revenues generated from consumptive and non-consumptive use of the asset and their relative contribution to sustaining operations over time would ultimately be a function of the socio-economic conditions prevailing at the project location/s at various points in time over the life of the project. Initial experience appears to suggest that such additional revenues might be necessary but not sufficient to sustain RE projects operations - even debtfree projects with fully depreciated assets - and additional revenue streams might be required to attract investments into growing the RE sector.

In order to motivate project developers and operators to enhance the social sustainability of their RE ventures, this paper has recommended a capacity payment, in the manner of an option premium paid by the utility to secure the option to draw power from the plant, and a telescopic capacity payment scheme for generators, much like the telescopic ("block") tariff schemes that are offered to end-users. The major difference, however, would be that while end-user tariffs routinely rose with consumption, optimal generator-end capacity-payments might fall simultaneous with growing production. This is slated to help discover equilibrium tariffs based on marginal costs of production, and to accommodate the need for additional investments into storage to enable time-switching that might be mandated at higher levels of (intermittent) RE generation.

The principal component of project revenue is derived from the sale of electricity at prices discovered on competitive markets (consumptive use); the modest but fixed base-tariff may be designed in the manner of a capacity payment (existential use); additional revenues could be earned from tourism, depiction in popular culture, advertising, and the like (nonconsumptive use): the quantum of such revenues would be determined by the level of competition among generators in the market and the prevailing local circumstances and would call for active and dynamic management of the project asset. RE project initiatives would need to actively pursue such opportunities for additional revenues, even as such secondary sources of revenues might be insufficient to ensure the profitability of otherwise unviable but socially desirable ventures.

\footnotetext{
${ }^{5}$ A more detailed discussion on the definitions of Social Sustainability is presented within Vallance et al. [47].
} 


\section{References}

1. ABB (2018) A New Era of Solar Power. Renewable Energy World. https://www.renewableenergyworld.com/white-papers/2018/09/anew-era-of-solar-energy.html, last accessed 20 June 2018

2. AEE (2016) Energiewende Travel Guide Published in English. The German Renewable Energies Agency, 16 March, https://www. unendlich-viel-energie.de/english/\%E2\%80\%9Cgermanyexperience-renewable-energy $\% \mathrm{E} 2 \% 80 \% 9 \mathrm{C}$-explores-200destinations-and-the-progress-of-renewable-energy, last accessed 22 June 2018

3. Ambec S and Crampes C (2015) Paying for waste: without carbon pricing, subsidies to renewables can be counter-productive, The Economist, 30 November, https://www.economist.com/freeexchange/2015/11/30/without-carbon-pricing-subsidies-torenewables-can-be-counterproductive, last accessed 03 June 2018

4. Amin A (1996) Beyond associative democracy. New Polit Econ 1(3):309-333

5. Batel S (2018) A critical discussion of research on the social Acceptance of renewable energy generation and associated infrastructures and an agenda for the future. J Environ Policy Plan 20(3): 356-369

6. Beer M, Rybár R, Kal'avský M (2017) Renewable energy sources as an attractive element of industrial tourism. Curr Issue Tour. https://doi.org/10.1080/13683500.2017.1316971

7. Bell WP, Foster J (2017) Using solar PV feed-in tariff policy history to inform a sustainable flexible pricing regime to enhance the diffusion of energy storage and electric vehicles. J Bioecon 19(1):127145

8. Borenstein S and Bushnell J B (2018) Are residential electricity prices too high or too low? Or both? NBER Working Paper No. 24756, National Bureau of economic research http://www.nber.org/ papers/w24756, accessed 01 Aug 2018

9. Borenstein S (2008) The market value and cost of solar photovoltaic electricity production. CSEM WP 176, Center for the Study of energy Markets, University of California Energy Institute, https://ei. haas.berkeley.edu/research/papers/CSEM/csemwp176.pdf, last accessed 22 August 2018

10. Bushnell J and Novan K (2018) Setting with the sun: the impacts of renewable energy on wholesale power markets. NBER Working Paper No. 24980, National Bureau of economic research, http:// www.nber.org/papers/w24980, accessed 06 September 2018

11. Couture T, Gagnon Y (2010) An analysis of feed-in tariff remuneration models: implications for renewable energy investment. Energy Policy 38:955-965

12. CIAL (2016) Organic Farming. CIAL Infrastructures Limited, a subsidiary of Cochin International Airport Limited, http:// cialinfra.in/Projects/ORGANIC-FARMING, last accessed 22 June 2018

13. Dance S (2018) A Wind Farm Developer Offered Ocean City Free Electricity, But Resort Town is Still Fighting Offshore Turbines. The Baltimore Sun, 11 Jun, http://www.baltimoresun.com/news/ maryland/environment/bs-md-ocean-city-wind-20180611-story. html\#nws=true, accessed 21 June 2018

14. Deign J (2018a) What happens when renewables eat their own profits? Greentech Media 29 May, https://www.greentechmedia. com/articles/read/what-happens-when-renewables-eat-their-ownprofits?utm_source $=$ Daily\&utm_medium $=$ email\&utm_campaign $=$ GTMDaily\#gs.ph2cdtw, last accessed 04 June 2018

15. Deign J (2018b) South Africa open again for renewables after auction turmoil. Greentech Media, 05 July, https://www. greentechmedia.com/articles/read/south-africa-open-again-forrenewables-after-auction-turmoil?utm_source=Daily\&utm medium=email\&utm campaign=GTMDaily\#gs.JLH2Y o, last accessed 7 July 2018
16. ET (2018) Kerala Hydel tourism Centre to expand activities to boost income. The Economic Times, 23 April, https:// economictimes.indiatimes.com/industry/services/travel/keralahydel-tourism-centre-to-expand-activities-to-boost-income/ articleshow/63882591.cms, last accessed 22 May 2018

17. Ford N (2018) MidAmerican wind repowering targets $28 \%$ output hike, longer returns. New Energy Update, 25 July, http:// newenergyupdate.com/wind-energy-update/midamerican-windrepowering-targets-28-output-hike-longer-returns?utm_campaign= NEP\%20WIN\%2025JUL18\%20Newsletter\%20Version\%20B\% $20 \% 28$ Wind $\% 20 \mathrm{DB} \% 29 \&$ utm_medium $=$ email\&utm_source $=$ Eloqua\&elqTrackId=30e33b3e6c1b48e09423baa435ce39b1\&elq= 345df489a9be4f6b914b86cd24245f13\&elqaid=38060\&elqat $=$ 1\&elqCampaignId=20379,

18. Foxon TJ, Base CSE, Busch J, Bush R, Hall S, Roelich K (2015) Low carbon infrastructure investment: extending business models for sustainability. Infrastruct Complex 2(4):1-13. https://doi.org/10. 1186/s40551-015-0009-4

19. Frankel D, Perrine A and Pinner D (2016) How Solar Energy Can (Finally) Create Value. Mckinsey \& Company, https://www. mckinsey.com/business-functions/sustainability-and-resourceproductivity/our-insights/how-solar-energy-can-finally-createvalue

20. Frantál B, Urbánková R (2017) Energy tourism: an emerging field of study. Curr Issue Tour 20(13):1395-1412

21. Gerdes J (2019) Daimler and Statkraft unveil PPA for German wind farms after feed-in tariff expiration. Greentech Media, 01 January, https://www.greentechmedia.com/articles/read/daimler-statkraftunveil-ppa-for-electricity-from-german-wind-farms\#gs.idYkhUSp

22. Gerdes J (2018) Germany faces Gigawatt - scale loss of onshore wind power. Greentech Media, 25 May, https://www. greentechmedia.com/articles/read/germany-faces-a-gigawatt-scaleloss-of-onshore-wind-power\#gs.iNPkpcI

23. Gosling M (2018) Renewables: green light for green energy as Radebe signs purchase agreements. The Daily Maverick, 4 April 2018, https://www.dailymaverick.co.za/article/2018-04-04renewables-green-light-for-green-energy-as-radebe-signspurchase-agreements/\#.Wxtu1UiFNPY,

24. Groba F, Indvik J and Jenner S (2011) Assessing the strength and effectiveness of renewable electricity feed-in-tariffs in European Union countries, DIW Discussion Paper No. 1176, Deutsches Institut für Wirtschaftsforschung, Berlin, Germany

25. Heap R (2018) Wind is progressing - but we Can't be blind to the threats. A Word About Wind, 8 June 2018, https://mailchi.mp/ awordaboutwind $/ 8$ th-june-2018?e=3f80920d77 last accessed 9 . June 2018

26. Imelda, Fripp M, Roberts MJ (2018) Variable Pricing and the Cost of Renewable Energy. NBER Working Paper 24712, National Bureau of Economic Research, http://www.nber.org/papers/ w24712, p. 33 of 49

27. Innergex (2018a) 2017 - Annual Report, Innergex Renewable Energy Inc, 21 February, https://www.innergex.com/wp-content/ uploads/2017-Annual-Report.pdf, p. 57 of 155, last accessed 09 January 2019

28. Innergex (2018b) Q3-2018 - Quarterly Report, Innergex Renewable Energy Inc, 26 November, https://www.innergex.com/ wp-content/uploads/Q3-2018-EN.pdf , p. 44 and 46 of 104, last accessed 09 January 2019

29. Ito K (2014) Do consumers respond to marginal or average Price? Evidence from nonlinear electricity pricing. Am Econ Rev 104(2): 537-563

30. Ladenburg J (2010) Visual impact assessment of offshore wind farms and prior experience. Appl Energy 86(3):380-387

31. Lesser JA, Su X (2008) Design of an Economically Efficient Feedin Tariff Structure for renewable energy development. Energy Policy 36:981-990 
32. Liebreich M (2017) Six design principles for the power Markets of the Future - a personal view. Bloomberg new energy finance, 24 May, https://data.bloomberglp.com/bnef/sites/14/2017/05/ Liebreich-Six-Design-Principles-for-the-Power-Markets-of-theFuture.pdf,

33. Lines A (2014) Thrill-seekers and James bond fans Queueing up to recreate iconic GoldenEye contra Dem bungee jump. Mirror, 28 August, https://www.mirror.co.uk/news/world-news/thrill-seekersjames-bond-fans-queueing-4119185,

34. Martiskainen M, Heiskanen E, Speciale G (2018) Community energy initiatives to alleviate fuel poverty: the material politics of energy Cafés. Local Environ 23(1):20-35

35. Mendonça M. and Jacobs D. (2009) Feed-in tariffs go global: policy in practice. Renewable Energy World 12(4), 17 September, https:// www.renewableenergyworld.com/articles/print/volume-12/issue-4/ solar-energy/feed-in-tariffs-go-global-policy-in-practice.html,

36. Merchant E F (2018) If solar and wind hit $50 \%$ of generation, US wholesale energy prices could fall $25 \%$ of more. Greentech Media, 16 May, https://www.greentechmedia.com/articles/read/energyprices-if-wind-and-solar-hit-50-percent-of-generation\#gs. MyKamjE,

37. Nabiyeva K (2014) Renewables as tourist attractions? Only in Germany. Climate Central, 17 June, http://www.climatecentral. org/news/renewable-energy-as-tourist-attractions-ingermany17558 ,

38. Nadaï A, van der Horst D (2010) Introduction: landscapes of energies. Landsc Res 35(2):143-155. https://doi.org/10.1080/ 01426390903557543

39. Polo AL, Haas R (2014) An international overview of promotion policies for grid-connected photovoltaic systems. Prog Photovolt Res Appl 22:248-273

40. Povitkina M (2018) The limits of democracy in tackling climate change. Environ Polit 27(3):411-432. https://doi.org/10.1080/ 09644016.2018 .1444723
41. S\&W (2014) Martifer solar delivers first grid parity project in Italy to IKEA. Sun \& Wind Energy, 6 May, http://www.sunwindenergy. com/photovoltaics-pressreleases/martifer-solar-delivers-first-girdpartity-project-italy-ikea,

42. Scognamiglio A (2016) 'Photovoltaic landscapes': design and assessment. A critical review for a new Transdisciplinary design vision. Renew Sust Energ Rev 55:629-661

43. Sherren K, Beckley TM, Parkins JR, Stedman RC, Keilty K, Morin I (2016) Learning (or living) to love the landscapes of hydroelectricity in Canada: eliciting local perspectives on the Mactaquac dam via Headpond boat Tours. Energy Res Soc Sci 14:102-110

44. Singh S. (2018) Depreciated Power Assets Must Result in Tariff Reduction, Proposes New Tariff Policy. Energy World, 04 June, https://energy.economictimes.indiatimes.com/news/power/ depreciated-power-assets-must-result-in-tariff-reduction-proposesnew-tariff-policy/64443084,

45. Srinivasan S (2013) Solar Photovoltaics: Oligopsony, non-market decision-making and the paradoxical persistence of unprofitability. I. J Green Econ 7(2):116-147

46. Upreti P M (2018) Bustards: down to the wire. The Hindu BusinessLine Blink, 2 June 2018, p 14 of 24

47. Vallance S, Perkins HC, Dixon JE (2011) What is social sustainability? A clarification of concepts. Geoforum 42(3):342-348

48. van den Bergh J, Folke C, Polasky S, Scheffer M, Steffen W (2015) What if solar energy becomes really cheap? A thought experiment of environmental problem shifting. Curr Opin Environ Sustain 14: 170-179

49. Wolsink M (2018) Co-production in distributed generation: renewable energy and creating space for fitting infrastructure within landscapes. Landsc Res 43(4):542-561. https://doi.org/10.1080/ 01426397.2017 .1358360

Publisher's Note Springer Nature remains neutral with regard to jurisdictional claims in published maps and institutional affiliations. 